\title{
Study and Practice of "MOOC+" Online and Offline Mixed Accommodation-type Teaching Mode in Colleges and Universities
}

\author{
Jianjun $\mathrm{Gao}^{1}$, Tongguang Zhang ${ }^{1}$ \\ ${ }^{1}$ HeiLongJiang University of Technology, Jixi Heilongjiang, 158100, China
}

Key words: "MOOC+", Online and offline, Mixed accommodation-type, Teaching mode.

\begin{abstract}
MOOC+" online and offline mixed accommodation-type teaching mode in colleges and universities is a new teaching form integrating online MOOC learning and offline diversified and interactive learning which aims at giving full play to advantages of online and offline teaching and realizing complement of each other's advantages. This paper puts forward the method and approach for establishing "MOOC+" online and offline mixed accommodation-type teaching mode in colleges and universities on the basis of specifying its value connotation and aims at seeking for an offline teaching mode matched with MOOC, forming an interactive teaching mode, improving the academic performance of students and meanwhile strengthening their awareness of independent and active learning and training and improving their awareness of exploration, spirit of innovation and comprehensive quality.
\end{abstract}

\section{Introduction}

MOOC refers to massive open online course and originates from foreign institutions of higher learning. Learning subjects often study on the internet and watch videos, complete work and make discussions online. The most important value of MOOC is to create a large school with free access by anyone in the world by means of internet and drive the closed college class to transform towards an open and sharing era. However, we should be clearly aware that though MOOC can expand knowledge transfer and learning scope effectively, whether college students in China can accept and understand MOOC effectively requires our deeper thinking. At least, the growth background of Chinese college students is not completely matched with such course learning way. Most students have very weak abilities of independent learning and self-control. It is very difficult to make them persist in learning a course or some knowledge. Many students answer questions with specific answer provided by teachers mechanically under normal conditions. They lack interest in question answering and exploration and the ability of analyzing, discovering and exploring the answer of questions independently. In addition, as students only acquire knowledge through network teaching and follow the rhythm of instructors blindly, the overall classroom scene and atmosphere will lack and students will easily miss the sense of integration in the learning process and become attached to network teaching. It is obvious that simple MOOC learning form is not appropriate to the learning and growth of Chinese students currently. Specialized students require exchange and discussion with classmates and teachers in class or relevant places. How to make efficient use of advantages of "MOOC" in teaching to make up for the deficiency of traditional classroom teaching reasonably and conduct scientific and reasonable teaching? An ideal implementation plan is the use of "MOOC+" teaching mode currently.

"MOOC+" teaching mode is a new teaching mode integrating online MOOC learning and offline diversified and interactive learning which aims at giving full play to advantages of online and offline learning and realizing complement of each other's advantages. As online teaching in MOOC form can transfer knowledge efficiently, while face-to-face, scene-type, flipped-type and investigation \& discussion-type offline interactive teaching is conducive to the deepening and expansion of students' thinking and emotion communication and experience of students and teachers, they have very strong complement of each other's advantages. 


\section{Connotations of "MOOC+"}

MOOC is a teaching form centering on course video materials supplemented by various practice, test and experimental materials and a course mode in which students study by having practice and test while watching videos. Students generally watch teaching micro-video at home and complete preliminary understanding and mastery of teaching knowledge before class, and complete work, deepen discussions and conduct practical operation in class to deepen and consolidate knowledge understanding and mastery.

"MOOC+" is a new teaching mode integrating online teaching mode of MOOC and "+" which is an offline teaching mode centering on exploration and interaction. It is a perfect combination of online and offline education. MOOC teaching can transfer knowledge efficiently, while face-to-face discussion teaching in class is more conducive to the deepening and expansion of innovative thinking, emotion communication and experience enrichment. They can complement each other's advantages. It aims at seeking for an offline teaching mode matched with MOOC, finally forming an interactive teaching mode, realizing the improvement of educational quality, allowing students to study more independently and making knowledge comprehensive quality-based from knowledge-based.

\section{Value connotations of "MOOC+" online and offline mixed accommodation-type teaching mode in colleges and universities}

\section{Source of interest and independent exploration of ability improvement}

Interest is a power resource of learning. College education should provide education meeting the demand of each college student as far as possible and stimulate maximum potential of students in study by arousing their interest in learning. Students have adequate time for thinking and lookup in both MOOC learning and face-to-face learning and discussion in class. Therefore, they will have deeper and more comprehensive thinking on problems. In addition, students can learn and even study repeatedly at home or in the school independently before class according to their academic base and learning features. With respect to problems existing in learning and when they expect to exchange and share with others, they can seek help from teachers or classmates online or face to face. In this way, they can learn and solve problems at any time based on interest and their independence and initiative of learning will be improved greatly. The exchange of insights in groups in class and collective discussions and debate can not only improve the cognition, understanding and mastery of knowledge, but also improve students' abilities of language expression, communication and interpersonal relationship.

\section{Educational idea and training of comprehensive quality}

Education should give full play to its core function of cultivating, educating and influencing people. "MOOC+" online and offline mixed accommodation-type education mode provides adequate time and conditions for deeper communication between teachers and students and among students and meanwhile provides them with rare opportunities for more profound mutual influence and improvement. The integrated implementation of such mixed mode pays attention to students' further independent mastery of knowledge as well as the improvement and development of students' abilities and the training of their moral quality. With the constant advancement of such teaching mode, it not only develops students' cognitive level, angle, depth and breadth of thinking, completeness and uniqueness of analysis and ability of dialectical thinking to different extents, but also plays an important role in the improvement of students' personal virtue, emotional attitude, value, spirit of innovation, practical ability and physical and psychological health. 


\section{Impact and influence of "MOOC+" online and offline mixed accommodation-type teaching mode in colleges and universities}

\section{Impact and influence on students}

In traditional teaching mode, students have relatively weak abilities of independent learning, independent exploration and analysis and judgment over things. Most students generally do exercises mechanically and endlessly, answer questions with specific answer mechanically and have no interest in and ability of discovering and solving problems independently at most time. They have weak awareness of innovation and ability of independent exploration and study and lack the awareness and ability of innovation. The main purpose and pursuit of "MOOC+" online and offline mixed accommodation-type teaching mode in colleges and universities is to not only improve students' academic performance, but more importantly to enhance and train students' independent and active learning and train their awareness of exploration, spirit of innovation and comprehensive quality.

\section{Impact and influence on teachers}

Teachers using "MOOC+" online and offline mixed accommodation-type teaching mode need to handle technical activities related to MOOC and meanwhile have more systematic and deeper mastery of disciplinary knowledge. They should rearrange teaching knowledge according to MOOC features and teaching requirements on this basis and select appropriate method and contents for interaction with students and problem solution. Therefore, their teaching task and workload will further increase. Moreover, in terms of the role and behavior of teachers in class, they transform to the guide, organizer and helper of students in learning from the previous leader, initiator and explainer. These changes and requirements inevitably produce challenges and influence on teachers and drive them to change in time.

\section{Impact and influence on management system}

With further advancement of "MOOC+" online and offline mixed accommodation-type teaching mode and constant maturity and improvement of MOOC online learning, the future course teaching and knowledge impartment will have fundamental changes. Under the new teaching mode and situation, course teaching time, teaching assessment, evaluation, management awareness and form will be reformed to be adapted to it and even school organization form will be reformed to be adapted to the new teaching mode. Such changes will inevitably cause major reform and fundamental changes of school management system.

\section{Study and practice of "MOOC+" online and offline mixed accommodation-type teaching mode in colleges and universities}

How teachers make efficient use of open and diversified learning advantages of MOOC to make up for the deficiency of traditional classroom teaching in college teaching is always an issue requiring our further thinking in teaching reform and one of the main issues faced by the current educational reform. The purpose of "MOOC+" teaching form is to give full play to advantages of diversified mixing learning and realize complement of each other's advantages. "MOOC+" online and offline mixed accommodation-type teaching mode in colleges and universities requires teaching team to propose an optimal teaching mode pertinent to each knowledge point and prepare teaching video, test and personalized guiding strategies representing the highest level of the teaching and research group or lesson preparation group through exchange and discussion. It turns classroom into a place for knowledge exploration, in-depth thinking and mutual practice between teachers and students based on advanced teaching concept and flexible and rich educational method of MOOC and establishes a brand new accommodation-type teaching mode with learners as the center, ability improvement as the core and the training of explorative awareness and spirit of innovation as fundamental. It aims at strengthening and training students' awareness of independence and initiative, spirit of innovation and comprehensive quality and attempts to change the thinking and behavior of learners fundamentally. 


\section{MOOC + flipped classroom teaching mode}

The integration of MOOC + flipped classroom teaching mode aims at realizing the complement of advantages of face-to-face classroom teaching and network online learning. Its outstanding function consists in the prior knowledge impartment and knowledge internalization and optimization. Classroom is a process of mutual cooperation and joint completion of teaching tasks by teachers and students, mainly involving interactive question answering and discussions between teachers and students. In flipped classroom, students conduct discussion and heuristic learning in groups; teachers supervise the learning of each group, integrate problems, focus on explaining common problems in learning, make indicative explanation in categories and groups for problems existing among some students and make pertinent explanation for individual problems so as to realize stratified and personalized teaching.

\section{MOOC + task-driving teaching mode}

MOOC + task-driving teaching mode requires breaking the traditional course knowledge system, recombining knowledge points and skill points according to job demands and designing task-driving MOOC contents on this basis. MOOC + task driving teaching mode reflects the teaching thought centering on students and driven by task with close combination of theory and practice.

\section{MOOC + question-driving teaching mode}

In MOOC + question-driving teaching mode, teachers divide teaching contents and set up key or core questions of course reasonably according to course knowledge point in combination with pertinent post of duty and task requirements of the major, design MOOC contents through core or key questions and introduce teaching contents. It aims at further understanding and mastering the knowledge involved through further exploration, analysis, thinking and inspiration of problems on the basis of problem cognition through MOOC and allowing students to draw inferences about other cases from one instance and then explore and master the essence of knowledge through in-depth problems layer by layer. It guides students to think deeply and actively, fully motivate the initiative of students and train their spirit of active thinking and positive exploration and innovation through the mode of "problem introduction - thinking guidance - problem discovery - problem analysis problem exploration - problem solution - problem inspiration- knowledge mastery".

\section{MOOC + exercise teaching mode}

MOOC + exercise teaching mode is formed through MOOC design with recombination of internal knowledge points of course according to knowledge points and skill points required by exercise teaching based on professional knowledge evolution rule and professional course objectives. Such mode can improve students' cognition more effectively. MOOC + exercise teaching mode is a teaching method combining students' integrated learning and teachers' guidance, which improves the perception of teaching, meets the requirement of explorative learning and the actual demand of mixed MOOC teaching and reflects the teaching thought of doing things and taste appreciation.

\section{MOOC + practice teaching mode}

MOOC + practice teaching mode is MOOC design with presentation and explanation of corresponding knowledge points through MOOC according to the requirement for correspondence of major to post and task objective, which allows students to have perceptual understanding and mastery of post operation, job task or knowledge and puts learners in practical environment through open practical teaching on this basis so that they can feel the practical atmosphere, conduct actual operation and post work, participate in work action in person, master problem research method and procedure and obtain perceptual inspiration and understanding and rational mastery.

\section{MOOC + second classroom activity teaching mode}

MOOC + second classroom activity teaching mode allows students to get more cognition and impetus based on the demonstration and presentation of professional core thought and technical requirements 
through MOOC, and realizes the promotion of learning, thinking, practice and use with competition through innovative practice and various competition activities.

"MOOC+" online and offline mixed accommodation-type teaching mode in colleges and universities realizes the transfer, reconstruction, internalization, consolidation and expansion of course knowledge, makes the learning purpose and direction of learners more specific and the teaching objective and direction of teachers clearer, creates a new teaching mode close to education and explores a mixed teaching mode and approach of joint education and training.

\section{Acknowledgement}

This paper is the achievement of a key topic of educational scientific planning of Heilongjiang Province in 2015 (topic approval No.: GJB1215064).

\section{References}

[1] Yi Qinghong. Study on Flipped Classroom Based on MOOC and Its Teaching Structure, Modern Education Technology, 2015,(25).

[2] Wu Changwei, Chen Jing, Deng Hong, Zou Yu. Study on Applied Undergraduate Mixed Teaching Mode Based on MOOC, Modern Education Science (Higher Educational Research), 2015,(3).

[3] Xiao Dongmei, Wu Xiuwen, Liu Fang. Deconstruction of MOOC Phenomenon from the Perspective of Educational Resource Allocation, Library, 2015,(5).

[4] Wu Min, Li Hui. Summary of MOOC Study, China Educational Technique \& Equipment, 2015,(12).

[5] Sun Nian, Zhang Youtang. MOOC Running Mode and Its Teaching Mechanism, Higher Education Development and Evaluation, 2015,(5). 